\title{
Erratum to: Efficacy of inundative releases of Trichogramma evanescens in controlling Lobesia botrana in vineyards in Egypt
}

Nabil E. El-Wakeil · Hamza Th. Farghaly •

Zakia A. Ragab

Published online: 18 May 2010

(C) Springer-Verlag 2010

Erratum to: J Pest Sci

DOI 10.1007/s10340-007-0184-7

This article has been retracted.

The online version of the original article can be found under doi:10.1007/s10340-007-0184-7.

N. E. El-Wakeil $(\varangle) \cdot$ H. Th. Farghaly · Z. A. Ragab

Pests and Plant Protection Department,

National Research Centre, Dokki, Cairo, Egypt

e-mail: n_emara@islamway.net 